\title{
Failure Investigation of a Blast Furnace Top Gas Recovery Turbine: Chronology and Mechanism
}

\author{
Kaushal Kishore (1) - Susovan Das · Himangshu Mandal - Omji Anand • \\ Goutam Mukhopadhyay • Manashi Adhikary • Anup Kumar
}

Submitted: 15 June 2020/Published online: 5 August 2020

(C) ASM International 2020

\begin{abstract}
Top gas recovery turbine (TRT) is used to utilize high top pressure for power generation in modern blast furnaces. A failure occurred in the TRT system that led to interruption in operation and reduced power generation. A large increase in vibration of turbine dischargeside bearing was reported prior to the failure. Failure investigation consisted of collection and analysis of plant data, on-site and visual observations, chemical analysis, microstructural analysis using optical and scanning electron microscope coupled with energy-dispersive spectroscopy and hardness measurements. Both the failed components, that is the connecting piece and the rotor blade, were composed of AISI 420 martensitic stainless steel. In the failed connecting piece, fatigue fracture characterized by ratchet and beach marks were identified to occur from a step, a potential stress concentration site. Analytical scanning electron microscopy revealed that the fatigue cracks originated from the corrosion pits having iron oxide scale rich in sulfur and chlorine. Pitting occurred due to breakage of passive chromium oxide film due to acidic water in the system containing high concentration of chlorine. Crack propagation occurred predominantly along the chromium carbide/tempered martensitic interface.
\end{abstract}

K. Kishore $(\bowtie) \cdot$ G. Mukhopadhyay $\cdot$ M. Adhikary $\cdot$ A. Kumar R\&D and Scientific Services, Tata Steel Limited, Jamshedpur, India

e-mail: kaushal.kishore3@tatasteel.com;

kaushal.memsiitb@gmail.com

S. Das · H. Mandal

Shared Services Technology Group, Tata Steel Limited,

Jamshedpur, India

O. Anand

Mechanical Maintenance, Tata Steel Limited, Jamshedpur, India
Stator blades failed subsequently in brittle mode. Lower hardness of the connecting pieces compared to the stator blade would have promoted fatigue failure in the former component. Based on the analysis, primary mode of failure is termed as "corrosion fatigue." Practical recommendations are provided to improve the reliability of the system.

Keywords Top recovery gas turbine - Corrosion fatigue Chloride $\cdot$ Pitting $\cdot$ Martensitic stainless steel

\section{Introduction}

Iron and steel industries are among the most energy-intensive sectors and are under constant pressure to reduce carbon footprint [1]. As such, serious attempts have been made in last few decades to standardize the practices of waste recovery and reuse. Top gas energy recovery turbine (TRT) is an efficient and established technology to recover the residual heat and energy of blast furnace gases after cleaning [2-4]. Blast furnace gases are commonly termed as "top gas," and therefore this technology to recover their energy using turbine is called "top gas energy recovery turbine (TRT)." It is believed that the output of TRT can meet up to $30 \%$ of the power requirement to run the entire blast furnace. Furthermore, the cooler blast furnace gas leaving the TRT unit is often used as fuel in the steel plant owing to its high calorific value. These characteristics of the TRT along with the fact that it requires only periodic maintenance have made it an integral part of most modern integrated steel plants.

Two distinct types of TRTs are used industrially, namely wet and dry TRTs. Figure 1 shows the simplified schematic indicating the flow of top gas from the blast 


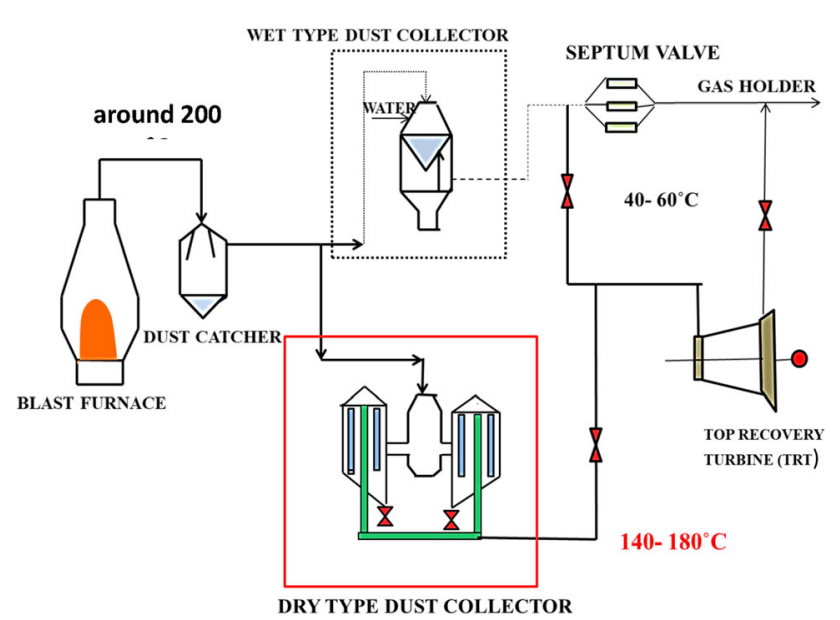

Fig. 1 Simplified schematic showing the flow of top gas from the blast furnace to the TRT

furnace at around $200{ }^{\circ} \mathrm{C}$ to different dust catchers (either dry or both dry and wet) and into the TRT for waste heat recovery. In the present case, wet TRT was in place. It was installed almost 10 years prior to the failure. This is a premature failure as the expected life as per the original equipment manufacturer (OEM) is 20 years, provided proper and timely maintenance is conducted. It should be noted that the last overhauling was done 2 years prior to the failure.

Failure analyses of turbine blades have been well documented in the literature. Some of the common mechanisms of failures of turbine blades are fatigue, abrasion, erosion, creep, corrosion, abnormal vibration, etc. [5-7]. However, most of the studies on the failures of turbine components are concentrated on the blades. Liu et al. [8] reported the failure analysis of TRT, but the study is principally different from the present case as the material was 17-4 precipitation-hardened stainless steel in contrast to martensitic stainless steel in the present case. Furthermore, they also concentrated their study on the rotor blades. In the present case, multiple fractures occurred including connecting pieces and stator blade. It is worth noting that most of the studies discuss failures of these blades in power plants having either gas turbine or steam turbine, where the conditions of temperature, pressure, and the corrosive media are largely different from a blast furnace's TRT. Thus, it became essential to investigate this unique failure in detail to arrive at logical conclusion regarding the mode and mechanism of failure and suggest for corrective actions. A schematic showing the arrangement of TRT is presented in Fig. 2.

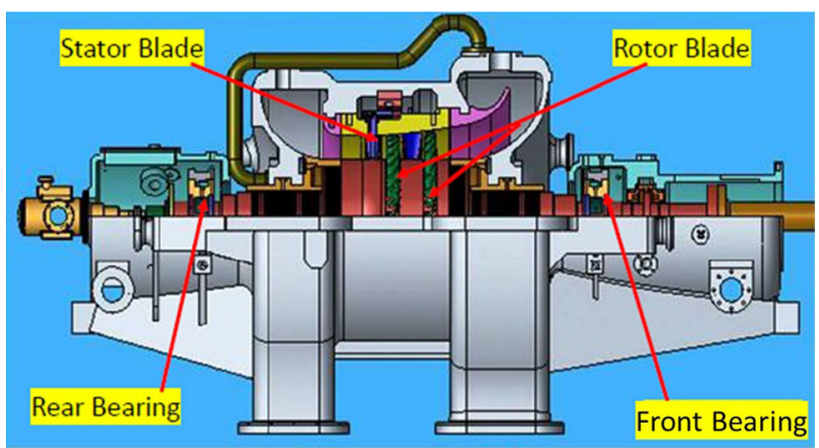

Fig. 2 Schematic showing the arrangement of TRT

\section{Investigation and Experimental Procedure}

The investigation started with the observations made at the location of failure. Important data related to vibration were collected. Broken parts of the connecting pieces and the stator blades were collected for fractographic, chemical and metallurgical analysis. Observations of the fracture surfaces were made using stereo microscope (Make: Leica; Model:M205 A). Chemical analysis was carried out using inductively coupled plasma mass spectroscopy (Make: Spectro, Model: Arcos) and x-ray fluorescence spectroscopy (Make: Thermo Fisher Scientific, Model: ARL 9900 Simultaneous-Sequential XRF series). Samples of the connecting piece and the rotor blade were cut using slow-speed disk cutter (Make: Chennai Metco, Model: Baincut, LSS: Low Speed Saw). Cross sections cut pieces were hot-mounted (Make: Pressi, Model: MecaPress 3) using bakelite-based polymeric powder. Scratch-free mirror-finished metallographic specimens were obtained using polishing (Make: MECAPOL, Model: P 320) up to 2000-grit silicon carbide emery papers followed by diamond pastes of $6 \mu \mathrm{m}, 3 \mu \mathrm{m}$ and $1 \mu \mathrm{m}$ sizes, respectively. These were etched to reveal the microstructural features using Vilella's reagent $(1 \mathrm{~g}$ picric acid $+5 \mathrm{ml}$ hydrochloric acid $+100 \mathrm{ml}$ ethanol). Microstructural analysis was conducted using optical microscope (Make: Leica, Model: DMRX) and scanning electron microscope (Make: Zeiss, Model: SUPRA 25) in unetched and etched conditions. Energy-dispersive x-ray spectroscopy (EDS) was conducted at $18 \mathrm{kV}$ voltage and $12 \mathrm{~mm}$ working distance. It was aimed at determining the nature of corrosion product associated with cracks. Micro-hardness measurements were carried out using Vickers hardness tester (Make: EMCO, Model: DuraScan). 


\section{Results}

\section{On-site Observations}

On June 29, 2019, at around 12:50 a.m., the vibrations of turbine discharge-side bearing increased sharply and tripped the system. Turbine bearing (discharge side) vibration which was already in alarming zone (93 micron) increased and crossed the trip limit of 160 micron within one second. The vibration trend is shown in Fig. 3. Vibration alarm and trip limit were 80 and 160 micron, respectively.

Figure $4 a$ and $b$ shows the overall images of the dismantled turbine. The condition of rotor blades is shown in Fig. $4 \mathrm{c}$ and $\mathrm{d}$. These blades got bent, had corroded appearance with surface pits and were broken at some of the edges. It seemed that these were struck with some objects and appeared to be secondary damages. A number of connecting pieces of the rotor blades had fractured. The location of these blades is marked in Fig. 5a-c. As shown in Fig. 5b, there was extensive deposition on these connecting pieces.

Failed samples were collected for further analysis. As shown in Fig. 6a, a number of connecting pieces had fractured. In contrast, only one stator blade got broken which is shown in Fig. 6b. In order to ascertain the maintenance condition of the nozzle, it was opened and checked. As shown in Fig. 6c, it was clogged. Water that came out was quite unclean (Refer Fig. 6d), and it was collected for analysis.

\section{Stereoscopic Observations}

Figure 7a shows the overall fracture surface of a representative connecting piece. In general, even after ultrasonic cleaning, fracture surface showed corroded appearance. Fracture plane coincided with a step where there is a change in cross section. Such steps can act as a stress concentration site. Fracture surface was flat, dull and smooth. Characteristic beach marks were observed as shown in Fig. 7b, c suggesting progressive fatigue mode of failure.

In contrast to the flat, smooth and dull fracture surface of the connecting piece, stator blade showed relatively shiny and granular fracture surface with multiple chevron marks indicating brittle mode of fracture (Fig. 8). These features are studied in greater detail using scanning electron microscope in the subsequent sections.

\section{Chemical Analysis}

Table 1 summarizes the chemical composition of a representative connecting pin and the stator blade. Chemical composition of all the connecting pieces (05) and stator blade matched closely with the AISI 420 martensitic stainless steel. This grade is typically used when a combination of strength and corrosion resistance is needed [9].

\section{SEM Fractography Coupled with EDS Analysis}

Fracture surface of the connecting piece is shown in Figs. 9 and 10. From the appearance of fracture surface and EDS analysis, the following important points should be noted:

(i) There are multiple ratchet marks on the fracture surface of the connecting piece. This suggests that fatigue cracks initiated from multiple locations. Fatigue fracture occurred from the location of

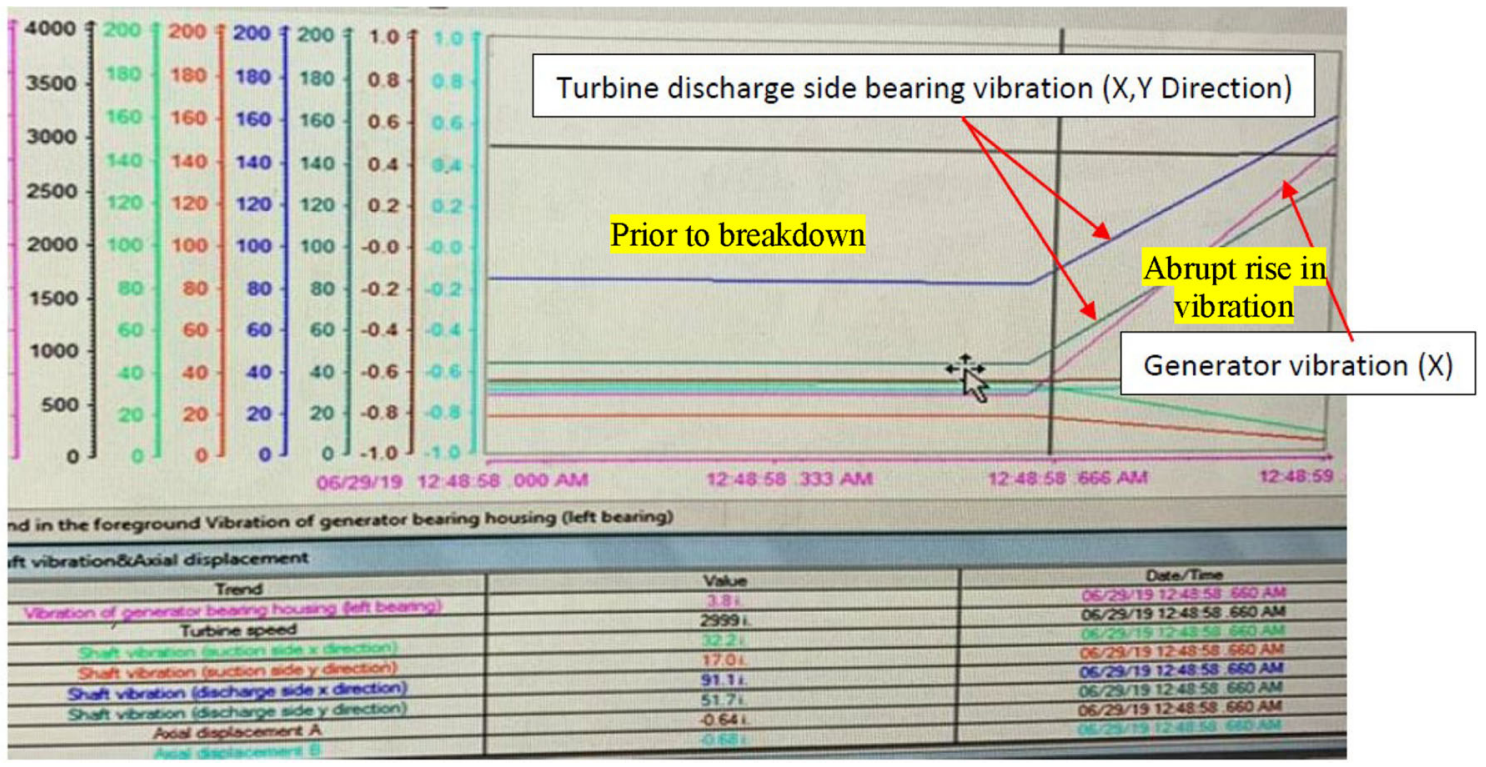

Fig. 3 Vibration data of turbine discharge-side bearing 
Fig. 4 On-site observations: (a) overall view of the dismantled turbine, (b) side view of the turbine with rotor blades, $(\mathbf{c}, \mathbf{d})$ closer view of the rotor blades showing extensive damage including deformation,

corrosion and blade rupture near its tip

Fig. 5 On-site observations of the turbine (continued): (a) location of connecting pieces, (b) closer view of connecting pieces showing severe

deposition, (c) location marked in drawing
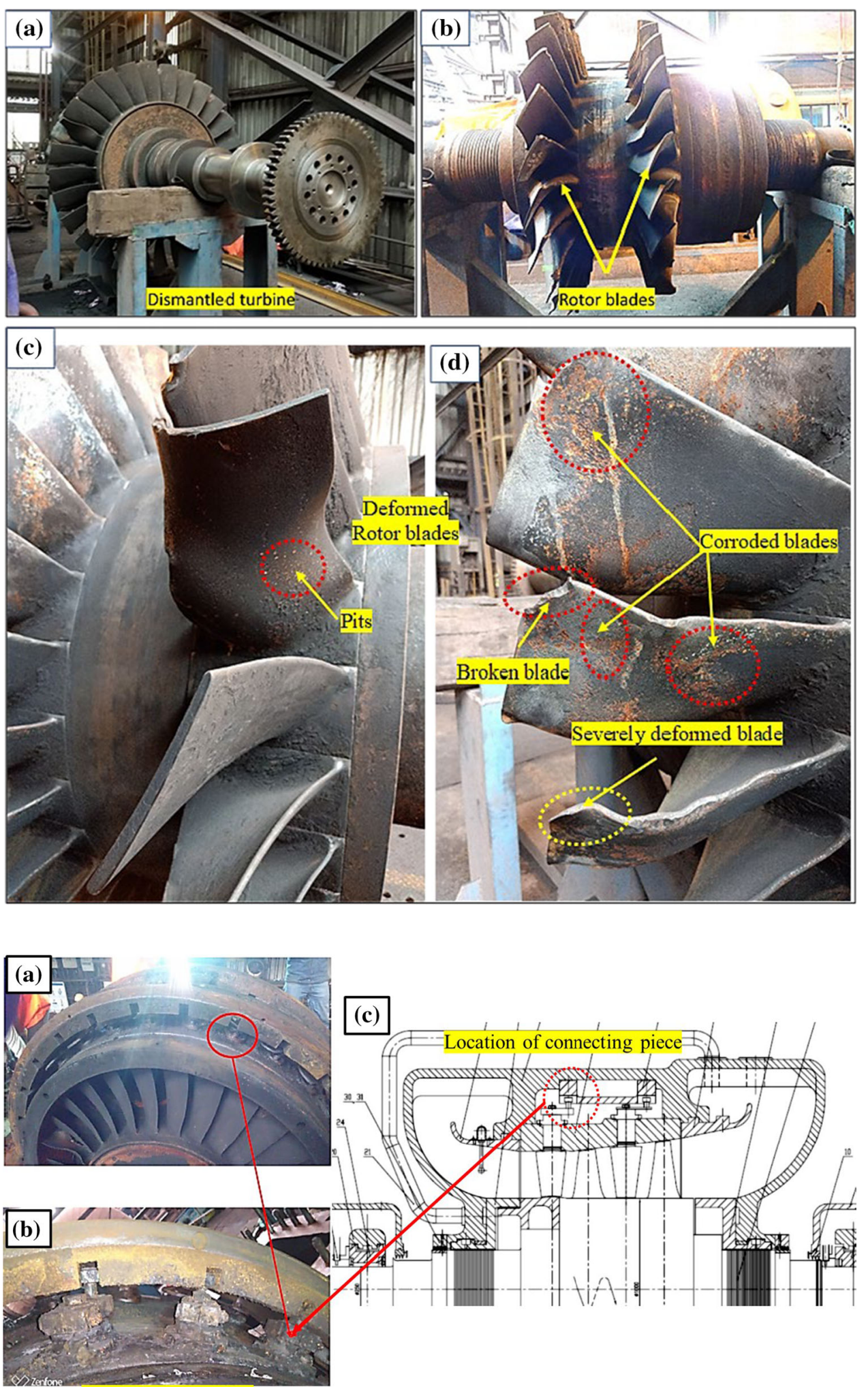

Severe deposition on

connecting pieces 
Fig. 6 Collected samples and evidence from the location of failure: (a) fractured connecting pieces, (b) broken stator blade, (c) clogged nozzle, $(\mathbf{d})$ unsatisfactory condition of the water coming out after opening the nozzle

Fig. 7 Stereoscopic images of the fracture surface of a representative connecting piece: (a) overall fracture surface, $(\mathbf{b}$, c) closer views showing characteristic beach marks
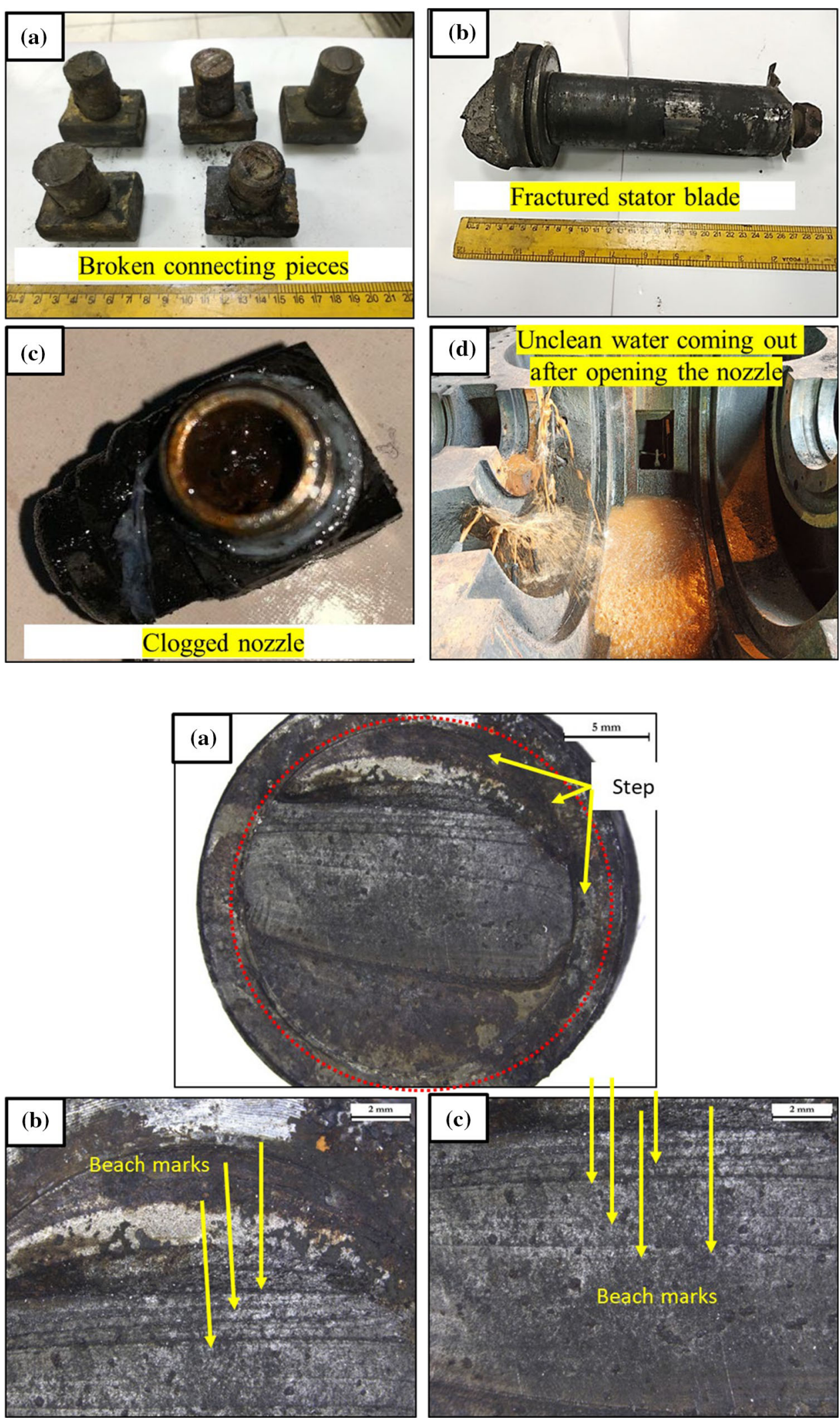
cross section change which acted as a stress concentration site.

(ii) There are machine marks near the fracture surface. These acted as stress concentration sites. Their presence can not only initiate fatigue but can be detrimental for corrosion resistance as well. The detrimental effect of mechanical stress/deformation on corrosion of stainless steel is well documented in the literature [10-12].

(iii) Fracture surface has corrosion products on it. Extensive cleaning revealed evidence of striations confirming fatigue mode of crack propagation (Ref. Figure 10). Each striation spacing corresponds to the length moved by the fatigue crack in a single cycle of loading and unloading. Similar features have been reported for different steel components such as piston rod, wire rope and crane hook under fatigue mode of fracture [13-15]. Ratchet marks and fatigue cracks appear to have their origin beneath the corrosion products.

(iv) Near the surface (EDS Point 1), there is a small area which appears to be the remnant of passive chromium oxide film. Stainless steels form passive layer of chromium oxide which prevents further corrosion. However, the film can be broken in the presence of chloride and sulfide ions [16]. Presence of sulfur and chlorine was detected at all

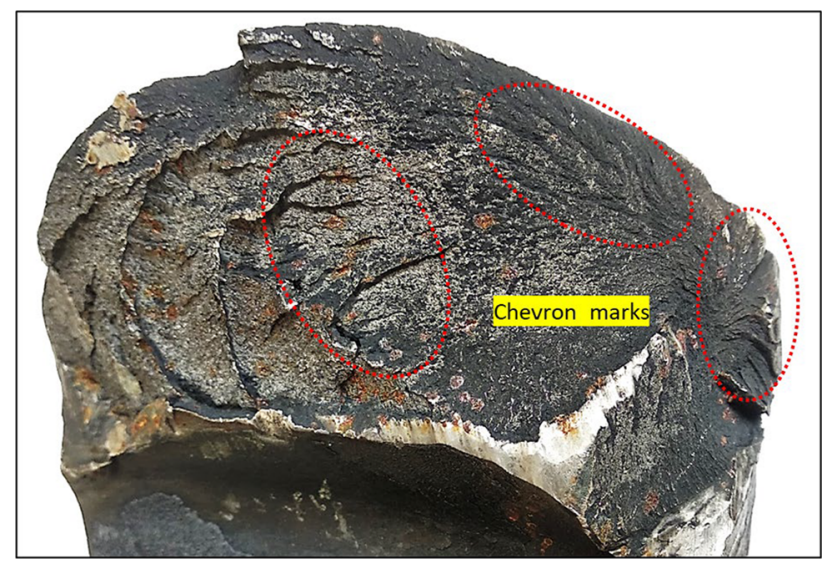

points. These elements can cause localized/pitting corrosion by breaking the passive film.

(v) Spectrums 3 and 4 correspond to the corrosion product from where fatigue cracks have originated (Table 2 ). In contrast to the point 1 , which showed a strong peak of chromium, these points are depleted of chromium and contain predominantly iron oxide along with sulfur, chlorine and calcium. This confirms that at this stage the passive film was broken and fatigue cracks subsequently initiated from such locations.

As shown in Fig. 11, cleavage fracture features which are typical of transgranular brittle fracture were observed in the case of failed stator blade. This further suggests that the failure of stator blade is secondary.

Microstructural Analysis and Hardness Measurements

Hardness of connecting piece is significantly lower as compared to the stator blade. This is despite the fact that both of them were made of the same martensitic stainless steel grade. The hardness value of the connecting piece was close to the AISI 420 grade when supplied in annealed condition. In contrast, hardness of stator blade lies in the range of quenched and tempered at $600{ }^{\circ} \mathrm{C}$ condition (Table 3). Hardness values corroborate well with the observed microstructures shown in Fig. 12. The temperature rarely exceeds $60{ }^{\circ} \mathrm{C}$ during service, and thus softening/over-tempering during service can be ruled out. A lower hardness of the connecting piece as compared to the quenched and tempered heat treatment condition can contribute to early crack initiation.

The following equation explains the relationship between the hardness of martensitic stainless steel and its fatigue strength $\left(S_{\mathrm{w}}\right)$ in the presence of small defect [18]:

$S_{\mathrm{w}}=h(H V+120) /\left(\operatorname{area}^{1 / 2}\right)^{1 / 6}$

where $h$ is a constant, $\mathrm{HV}$ is the hardness in HV10 and area is the defect area in (micron) ${ }^{2}$

Fig. 8 Fracture surface of the stator blade

Table 1 Chemical analysis of connecting piece and stator blade

\begin{tabular}{|c|c|c|c|c|c|c|c|c|c|c|}
\hline Sample & C & $\mathrm{Mn}$ & S & $\mathrm{P}$ & $\mathrm{Si}$ & $\mathrm{Al}$ & $\mathrm{Cr}$ & $\mathrm{Ni}$ & Mo & $\mathrm{V}$ \\
\hline Connecting piece & 0.220 & 0.380 & 0.022 & 0.023 & 0.284 & 0.027 & 12.64 & 0.143 & 0.049 & 0.052 \\
\hline Stator blade & 0.180 & 0.353 & 0.018 & 0.025 & 0.378 & 0.003 & 12.90 & 0.170 & 0.052 & 0.047 \\
\hline Spec. AISI 420 & 0.15 & 1.00 & 0.03 & 0.04 & 1.00 & $\ldots$ & $12.00-14.00$ & $\ldots$ & $\ldots$ & $\ldots$ \\
\hline Steel & Min & Max & Max & Max & Max & & & & & \\
\hline
\end{tabular}



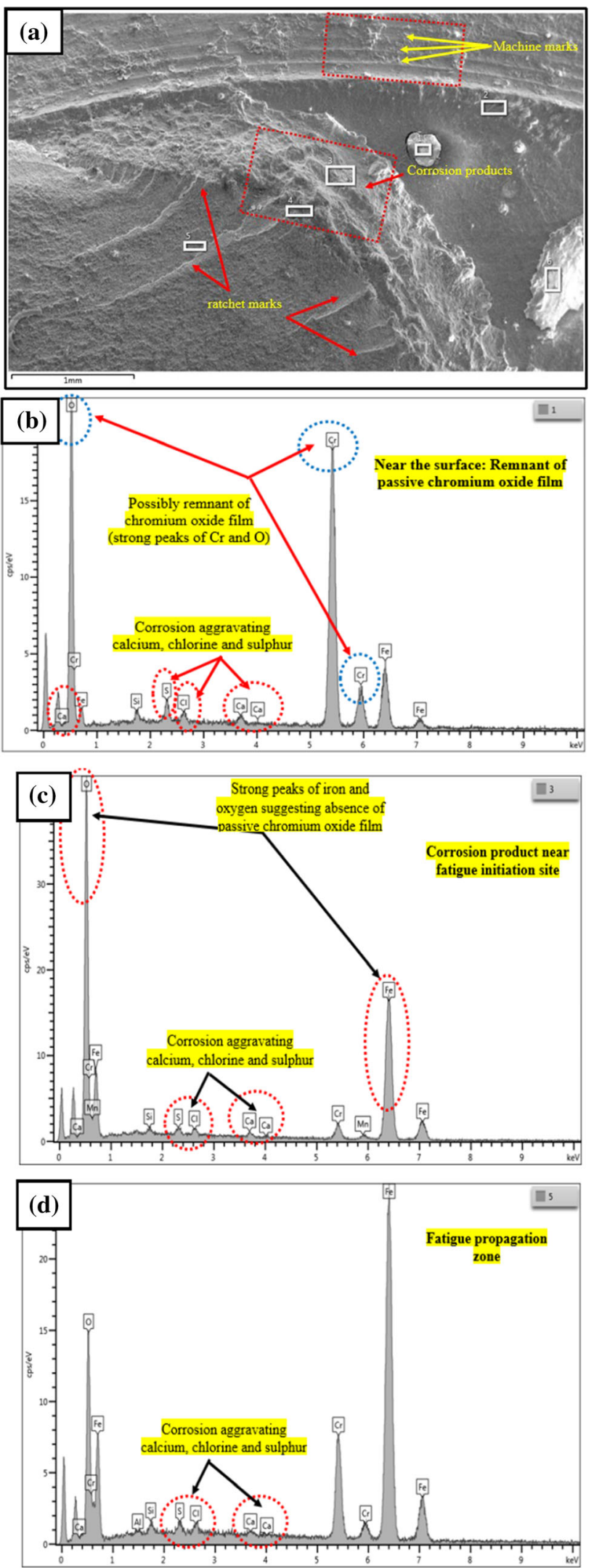

Fig. 9 SEM fractography showing fatigue features and corresponding EDS spectra

\section{SEM-EDS Analysis}

Figure 13a shows multiple cracks initiating from the corrosion pits. Although this can occur in the case of stress corrosion cracking as well as corrosion fatigue, the fact that distinct ratchet marks, beach marks and striations have been observed, it can be termed as "corrosion fatigue." Furthermore, as reported in the case of stress corrosion cracking (SCC) of wet coke quenching car liner, there is extensive crack branching and a combination of susceptible material, tensile stress and corrosive environment is required [19]. Therefore, the possibility of SCC can be ruled out. In the present case, cracks have propagated under the combined influence of corrosive environment and cyclic loading condition and their propagation is predominantly along the carbides/tempered martensite interfaces. This may be explained by the fact that a galvanic couple might have formed between anodic tempered martensite and cathodic chromium carbides and thus corrosion attack and crack propagation would have occurred preferentially adjacent to the carbides.

Elemental mapping shown in Fig. 14 confirms that the carbides dispersed in the tempered martensitic matrix are chromium carbides. Also, corrosion products which are present in the pit are mostly iron oxide (with some chromium in it) rich in sulfur, chlorine and calcium. These elements are present along the crack propagation path indicating their effect in lowering the fatigue life of the component. May et al. [20] have shown that fatigue life of a martensitic stainless steel in a chloride-containing environment is much lower than in air under cyclic condition.

In contrast to the coarse microstructure of the connecting piece, microstructure of the rotor blade consisted of lath martensite and fine dispersion of carbides as shown in Fig. 15. This explains the higher hardness of the blade compared to the connecting piece despite similar chemical composition.

\section{Determination of Source of Corrosive Elements}

Elements such as sulfur and chlorine can come from the top blast furnace gas or from the water in the circuit. Top BF could not be collected for the analysis. However, it can contain small amount of sulfur and chlorine. Water was collected, and its analysis is summarized in Table 4.

The $\mathrm{pH}$ of the water in the circuit suggests it to be acidic in nature. Furthermore, $369 \mathrm{ppm}$ of chlorine is quite high to break the passive chromium oxide film for initiation of pitting. There is calcium in water which is reflected in the corrosion product as well. 
Fig. 10 High-magnification SEM fractographs after extensive ultrasonic cleaning showing fatigue striations at two distinct locations

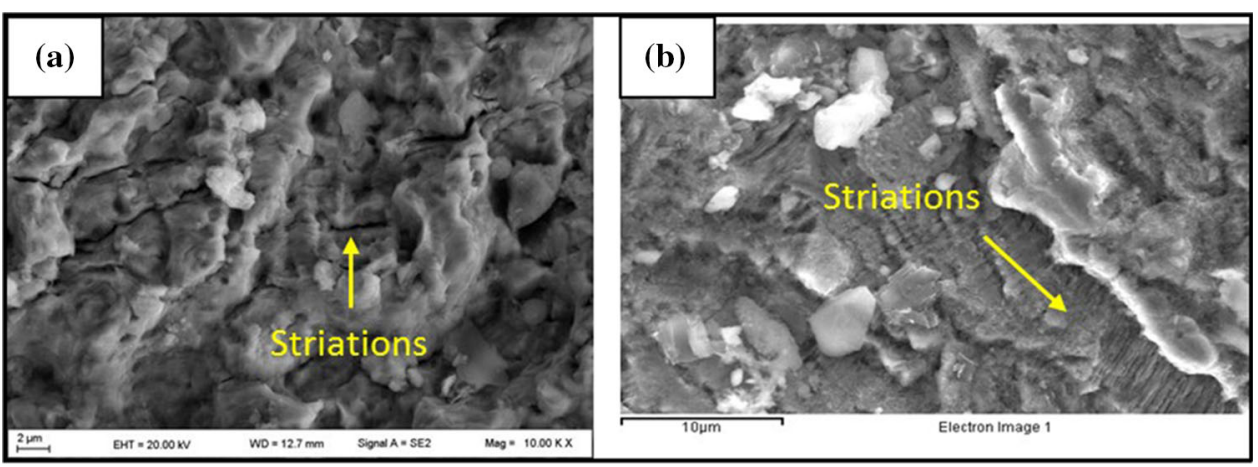

Table 2 Summary of EDS analysis of the fracture surface

\begin{tabular}{|c|c|c|c|c|c|c|}
\hline Spectrum label & 1 & 2 & 3 & 4 & 5 & 6 \\
\hline $\mathrm{O}$ & 27.53 & 17.16 & 41.38 & 33.17 & 15.06 & 34.64 \\
\hline $\mathrm{Al}$ & & 0.71 & & 0.95 & 0.35 & \\
\hline $\mathrm{Si}$ & 0.74 & 0.95 & 0.49 & 1.09 & 0.55 & 0.40 \\
\hline S & 1.41 & 0.81 & 0.62 & 0.71 & 0.56 & 0.40 \\
\hline $\mathrm{Cl}$ & 0.75 & 1.02 & 0.68 & 0.48 & 0.54 & 0.44 \\
\hline K & & 0.30 & & & & \\
\hline $\mathrm{Ca}$ & 0.67 & 0.86 & 0.54 & 0.76 & 0.27 & 0.37 \\
\hline $\mathrm{Cr}$ & 51.50 & 13.86 & 3.03 & 5.74 & 12.65 & 1.70 \\
\hline $\mathrm{Mn}$ & & & 0.64 & 0.73 & & \\
\hline $\mathrm{Fe}$ & 17.39 & 64.32 & 52.61 & 56.37 & 70.02 & 62.05 \\
\hline
\end{tabular}

Fig. 11 SEM fractography of stator blade at (a) $200 \times$, (b) $1000 \times$
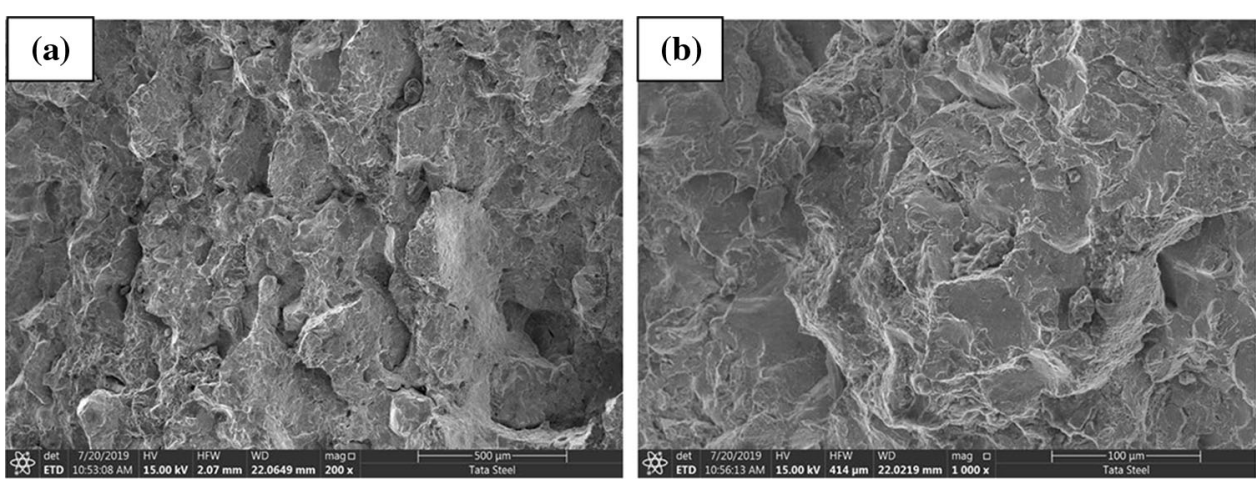

Table 3 Hardness values and comparison with ASTM standard [17]

\begin{tabular}{ll}
\hline Sample & Hardness (HV 10) \\
\hline Connecting piece & $189 \pm 4$ \\
Stator blade & $274 \pm 3$ \\
AISI 420 stainless steel & 210 minimum \\
(annealed) & \\
AISI 420 stainless steel & $275-300$ \\
(quenched and tempered at $600^{\circ} \mathrm{C}$ ) & \\
\hline
\end{tabular}

\section{Discussion}

Examination of fracture surfaces of connecting pieces and the stator blade paved the way for the determination of failure modes. Connecting pieces had smooth, dark and dull fracture surface with well-defined beach marks suggesting fatigue mode of failure under cyclic loading. The presence of striations further strengthened the fatigue mode of crack propagation. The change in aerodynamics by virtue of change in flow of blast furnace top gas, water 
Fig. 12 Optical micrographs of: (a) connecting pin, (b) stator blade
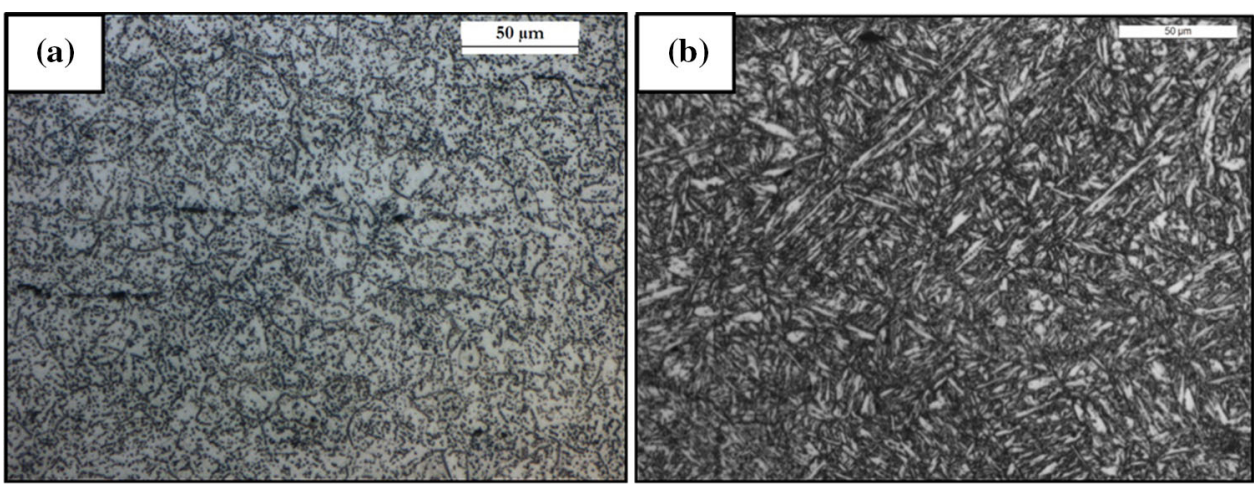

Fig. 13 SEM micrographs showing fatigue crack initiation and propagation in the connecting piece with respect to microstructural features
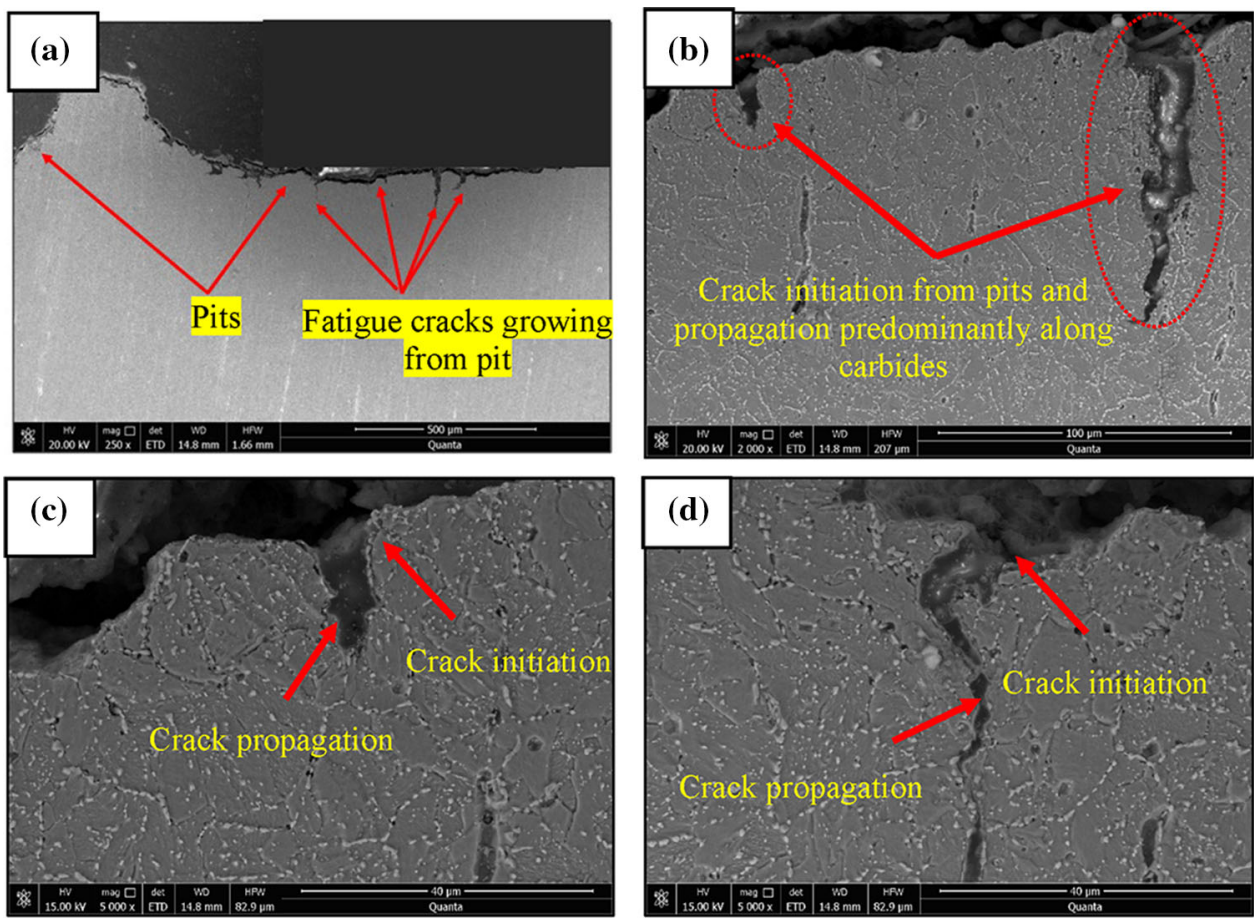

pressure and vibrations can be attributed as the possible sources of stress reversals. Fracture occurred from the step where there is cross section change, and it had machine marks which acted as stress raisers. In contrast to this, the fracture surface of the stator blade had granular appearance with chevron marks and cleavage planes indication transgranular brittle fracture, which may be an aftereffect or a secondary failure.

In order to establish the mechanism of fatigue failure in connecting pieces, SEM fractography was aided by indepth SEM-EDS analysis. It showed that fatigue cracks initiated from the corrosion pits. Formation of corrosion pits requires breakage of passive layer of chromium oxide, which was favored by the presence of chloride and sulfide in the environment. These elements are capable of breaking the passive film and forming the pits in martensitic stainless steels. Fatigue cracks propagated predominantly along the carbide/matrix interface under the combined influence of cyclic stresses (as suggested by beach marks and striations) and corrosive media (evident from the presence of iron oxide containing sulfur, chlorine and calcium along the path of the crack). Such a mechanism of crack initiation and propagation is termed as "corrosion fatigue." The lowering of fatigue life of martensitic stainless steel under the combined influence of cyclic stress and chloride containing media is well established in the literature [20].

It should be noted that in terms of selection of material, there was no mistake as AISI 420 martensitic stainless steel is usually used where a combination of fatigue strength and corrosion resistance is needed. However, the heat treatment cycle that the connecting piece was subjected to, that is 

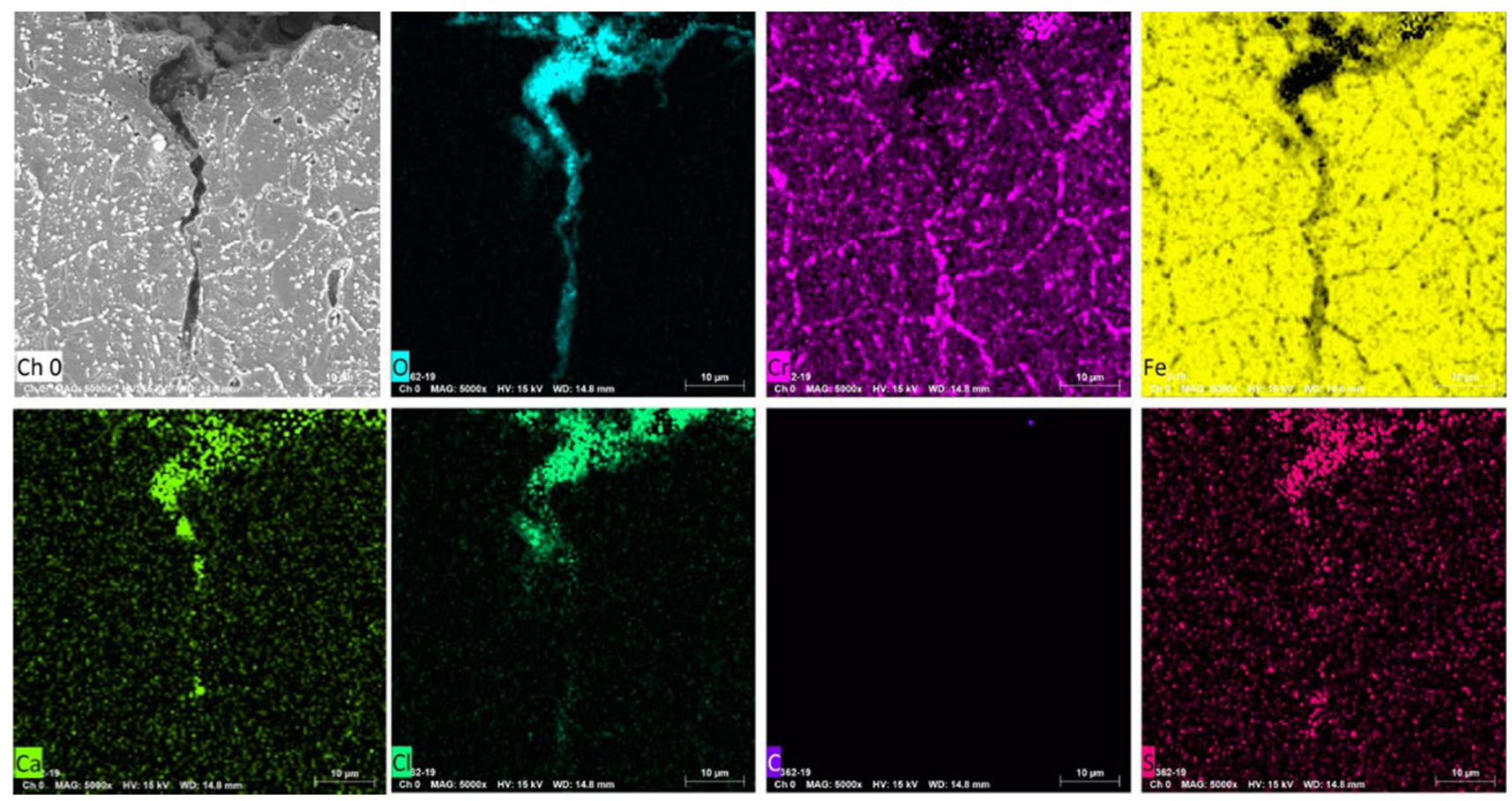

Fig. 14 EDS elemental mapping along the crack propagation path in the connecting piece

Fig. 15 SEM micrograph of the failed blade at (a) medium magnification, (b) higher magnification
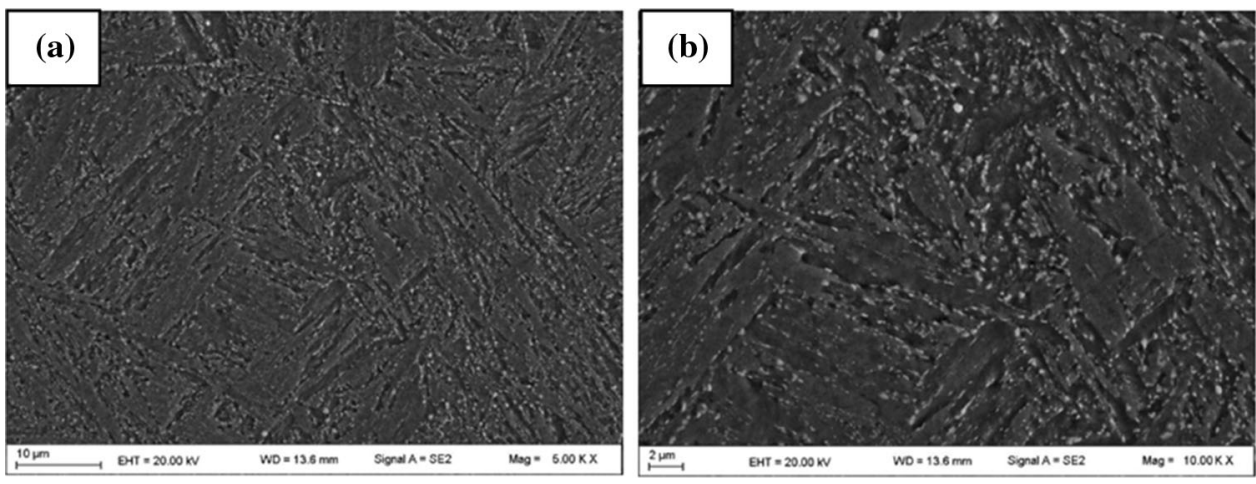

Table 4 Analysis of water collected from the TRT circuit

\begin{tabular}{ccccc}
\hline pH & $\begin{array}{c}\mathrm{Ca} \\
\text { (in ppm) }\end{array}$ & $\begin{array}{c}\mathrm{Mg} \\
(\text { in } \mathrm{ppm})\end{array}$ & $\begin{array}{c}\mathrm{Cl} \\
\text { (in ppm) }\end{array}$ & $\begin{array}{c}\text { Conductivity } \\
(\mu \text {-mho })\end{array}$ \\
\hline 6.1 & 22.4 & 7.5 & 369 & 295 \\
\hline
\end{tabular}

annealing, was not ideal as it resulted in lower hardness and thus lower fatigue strength.

An attempt has been made to determine the source of corroding species. It was observed that the water flowing through the circuit was quite dirty. Its characterization revealed that it contained very high concentration of chloride ions (> $300 \mathrm{ppm}$ ) and lower $\mathrm{pH}$ (around 6) rendering it acidic and conducive to break the passive film on martensitic stainless steel.
Based on the analysis, mechanism of failure of connecting piece is shown schematically in Fig. 16.

\section{Conclusions}

Based on the study, the following conclusions can be made:

(i) Connecting pieces failed in corrosion fatigue mode from the stepped portion which is a stress concentration site. Higher chloride content in the water and its acidic $\mathrm{pH}$ range led to the breakage of passive chromium oxide film followed by fatigue crack initiation and propagation along the carbide/matrix interface.

(ii) A lower hardness of the connecting piece resulted in reduced fatigue life. This is possibly due to 


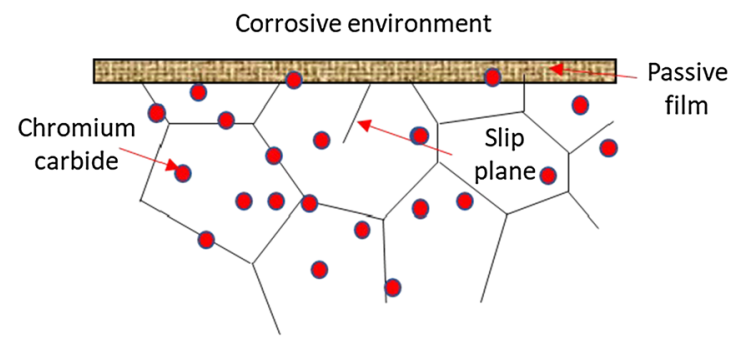

7.5 , and chlorine content should be less than $20 \mathrm{ppm}$.

- Nitrogen-added martensitic stainless steel or duplex stainless steel may be used as they have superior resistance to pitting corrosion [21].

- Hardness of the connecting pieces should be between 230 and $250 \mathrm{HV} 10$, and quality assurance plan (QAP) should be made.

Passive film breakage and pit formation by combined action of

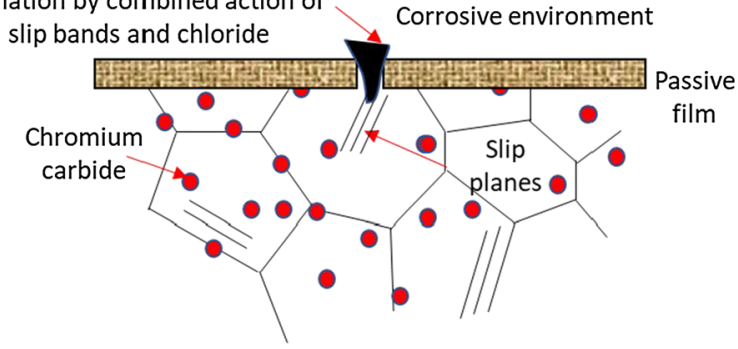

Passive film breakage and pit

formation by combined action of

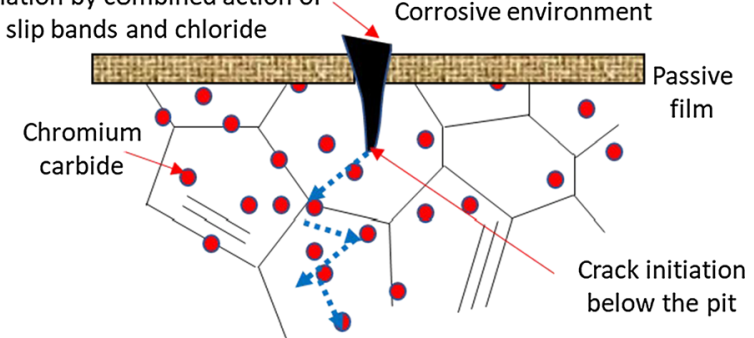

Fatigue crack propagation along matrix-chromium carbide interface due to formation of galvanic couple

Fig. 16 Proposed mechanism of corrosion fatigue in 420 martensitic stainless steel connecting piece

annealing heat treatment as against the desired quenching and tempering heat treatment cycle.

(iii) Failure of stator blade is secondary in nature, which is a transgranular brittle fracture.

(iv) In order to prevent recurrence of such failures, it is essential to monitor and maintain the quality of water with respect to $\mathrm{pH}$ and chloride content. Furthermore, the quality of the connecting pieces with respect to proper quenching and tempering heat treatment to achieve desired fatigue strength and machining guidelines should be maintained. Nitrogen-added martensitic stainless steel can also be helpful to enhance the pitting resistance.

(v) Following measures are recommended to prevent similar failures in the future and to improve the reliability of the TRT:

- Quality of water in the circuit must be monitored and controlled with $\mathrm{pH}$ range $7-$

\section{References}

1. Z. Qi et al., Using forest area for carbon footprint analysis of typical steel plant in China. Resour. Convers. Recycl. 132, 353360 (2018)

2. K. Tanaka, A comparison study of EU and Japan methods to assess $\mathrm{CO}_{2}$ emission reduction and energy saving in the iron and steel industry. Energy Policy 51, 578-585 (2012)

3. J.L. Zhang et al., Energy saving technologies and productive efficiency in the Chinese iron and steel sector. Energy 33, 525537 (2008)

4. M.T. Johansson et al., Options for the Swedish steel industryenergy efficiency measures and fuel conversion. Energy 36, 191198 (2011)

5. M.R. Jahangiri et al., Cement kiln dust induced corrosion fatigue damage of gas turbine compressor blades-a failure analysis. Mater. Des. 62, 288-295 (2014)

6. S. Qu et al., Failure analysis of the 1st stage blades in gas turbine engine. Eng. Fail. Anal. 32, 292-303 (2013)

7. M. Rao et al., Failure analysis of a low-pressure turbine blade in a coal-based thermal power plant. J. Fail. Anal. Prev. 15, 750-757 (2015)

8. M. Liu, Experimental investigation of failure behavior of the cracked $17-4 \mathrm{PH}$ steel blades in a top gas energy recovery turbine. Eng. Fail. Anal. 105, 545-554 (2019)

9. L. Lai et al., Stainless Steels: An Introduction and Their Recent Developments (Bentham Science Publishers, Sharjah, 2012)

10. L. Jinlong et al., The effect of pre-deformation on corrosion resistance of the passive film formed on 2205 duplex stainless steel. J. Alloys Compd. 686, 176-183 (2016)

11. N. Solomon et al., Effect of deformation-induced phase transformation on AISI 316 stainless steel corrosion resistance. Eng. Fail. Anal. 79, 865-875 (2017)

12. K. Kim et al., Effect of plastic deformation on the corrosion resistance of ferritic stainless steel as a bipolar plate for polymer electrolyte membrane fuel cells. Int. J. Hydrogen Energy 37, 8459-8464 (2012)

13. K. Kishore, M. Adhikary, Metallurgical investigation and life cycle assessment of a piston rod of thin slab caster. J. Fail. Anal. Prev. 19(5), 1407-1419 (2019)

14. K. Kishore, G. Mukhopadhyay, Novel degradation mechanism of a structural wire rope during its life cycle. Metallogr. Microstruct. Anal. 8(2), 189-200 (2019)

15. K. Kishore et al., Failure analysis of a $24 \mathrm{~T}$ crane hook using multi-disciplinary approach. Eng. Fail. Anal. 115, 104666 (2020). https://doi.org/10.1016/j.engfailanal.2020.104666

16. P. Marcus, Corrosion Mechanisms in Theory and Practice, Third Edition, CRC Press (2012) Chapters 1, 5, 6, 7, 10 and 11

17. Standard Specification for Martensitic Stainless Steel Forgings and Forgings Stock for High Temperature Service, ASTM A1021/A1021M-05 (2015) 
18. B. Schonbauer et al., Effect of small defect on the fatigue strength of martensitic stainless steels. Int. J. Fatigue 127, 362-375 (2019)

19. K. Kishore, G. Mukhopadhyay, Failure analysis of liner plates of wet coke quenching car. J. Fail. Anal. Prev. 19(3), 771-776 (2019)

20. M. May et al., Modelling of corrosion fatigue crack initiation on martensitic stainless steel in high cycle fatigue regime. Corros. Sci. 133, 397-405 (2018)
21. A. Ono et al., The corrosion resistance of nitrogen bearing martensitic stainless steels. ISIJ Int. 36, 813-817 (1996). https:// doi.org/10.2355/isijinternational.36.813

Publisher's Note Springer Nature remains neutral with regard to jurisdictional claims in published maps and institutional affiliations. 